\title{
D.E. Neuenschwander: Emmy Noether's Wonderful Theorem
}

\author{
Johns Hopkins University Press, Baltimore, 2011, 228 pages. \\ Intended for senior undergraduate physics students
}

\section{Fedde Benedictus}

Received: 23 March 2011 / Accepted: 4 May 2011 / Published online: 19 May 2011

(C) The Author(s) 2011. This article is published with open access at Springerlink.com

Many readers will remember their choice to study physics as the beginning of an attempt to grasp its very foundations. The first courses might have been a bitter pill. Instead of plunging into wonderful depths of miraculous insight, the student is expected to spend months and months to gain what seems a superficial understanding of the mathematics that underlies it all. Only then—and still only gradually—our student familiarizes himself with the deeper-lying beauty of theoretical physics. These circumstances call for an intellectual variant of a bottom-grab-sampler, to enable the student to behold the wondrous intricacies that lie far below.

In his book "Emmy Noether's Wonderful Theorem" it is precisely such a sampler Neuenschwander provides the reader with. Putting over thirty years of educational experience to good use, he manages to explain advanced topics in different field theories starting out with classical concepts. The book is a clear and concise explanation of the intricate relation between the concepts of conservation, invariance and symmetry in physics, larded with historical and philosophical sidetracks-extending the what? to the why? and where?

At the end of every chapter there are a number of exercises, which not only serve to test the student's understanding, but also to acquaint him with possible applications of the learned material. The exercises are accompanied by 'Questions for Reflection and Discussion', which again proves that Neuenschwander extends the what? to the why? and where? The work is supplemented by several short appendices in which non-essential concepts are derived more rigorously, without loosing the clarity of explanation which so graced the main body of the work.

F. Benedictus $(\bowtie)$

Utrecht University, Utrecht, Netherlands

e-mail: f.j.benedictus@uu.nl 
Besides enabling students to reach concepts which might otherwise have taken years to grasp, Neuenschwander's amicable, almost compassionate, style of explanation will surely compel many of his readers to become, like himself, 'Noether theorem enthusiasts'. These characteristics make the book very useful for an introductory course in relativity theory.

Open Access This article is distributed under the terms of the Creative Commons Attribution Noncommercial License which permits any noncommercial use, distribution, and reproduction in any medium, provided the original author(s) and source are credited. 